\section{Canakinumab for Childhood Sight-threatening Refractory Uveitis: A Case Series}

\section{To the Editor:}

Pediatric noninfectious uveitis embraces a group of inflammatory eye diseases responsible for severe ocular complications and blindness. Therapeutic options encompass topical or systemic steroid therapy, conventional immune-modulatory therapy, and tumor necrosis factor- $\alpha$ (TNF- $\alpha$ ) antagonists ${ }^{1}$. The use of anti-TNF- $\alpha$ modifier immunosuppressant treatment may apply to refractory cases ${ }^{2}$. Canakinumab is a human monoclonal antibody (IgG1) directed against interleukin $1 \beta$. It has been successfully used in cryopyrin-associated periodic syndromes ${ }^{3}$, systemic-onset juvenile idiopathic arthritis (JIA $)^{4}$, refractory Behçet disease ${ }^{5,6}$, and colchicine-resistant familial Mediterranean fever ${ }^{7}$. Preliminary evidences suggest the efficacy of canakinumab for refractory eye diseases in patients affected by Blau syndrome ${ }^{8}$, juvenile Behçet syndrome ${ }^{9}$, and chronic infantile neurologic cutaneous and articular syndrome ${ }^{10}$. Here we report 2 children affected by refractory sight-threatening uveitis who have been successfully treated with canakinumab.

Case 1. A 6-year-old boy was referred to our center for severe idiopathic uveitis, presenting with bilateral cataract, vitreous inflammatory exudation, and severe visual loss (right eye 20/32, left eye 20/50). The intraocular pressure was within the normal limits. Clinical history and ocular findings were consistent with the diagnosis of intermediate idiopathic uveitis.

On admission, intravenous steroid treatment was started (methylprednisone $30 \mathrm{mg} / \mathrm{kg} / \mathrm{day}$ for 3 days), followed by oral prednisone (1-2 $\mathrm{mg} / \mathrm{kg} / \mathrm{day}$ ) and methotrexate (MTX; 10-15 $\mathrm{mg} / \mathrm{m}^{2}$ weekly). Despite the initial remission, during steroid tapering over 4 months, he developed vitreal snow banks, vitreomacular traction, and retinal schisis, requiring surgical treatment. We decided to discontinue MTX and introduce adalimumab (ADA; $24 \mathrm{mg} / \mathrm{m}^{2}$ every 2 weeks). Throughout the followup, recurrent uveitis flare with cystoid macular edema were documented; hence, after 18 months of treatment, ADA was substituted with abatacept (ABA; $10 \mathrm{mg} / \mathrm{kg}$ every 4 weeks). This was used for a period of 7 months; nonetheless, ophthalmologic examination highlighted persistence of ocular inflammation (vitreitis) and macular edema (Figure 1A). Given the steroid dependence, the poor response to previous therapies, and the high risk of visual loss, we suggested the switch to canakinumab.

Case 2. A 9-year-old girl was referred to our hospital for recurrent uveitis associated to JIA. At a different hospital, a previous therapeutic attempt with MTX $\left(15 \mathrm{mg} / \mathrm{m}^{2} /\right.$ week $)$ and infliximab $(5 \mathrm{mg} / \mathrm{kg} / \mathrm{dose})$ had soon been discontinued because of allergic reaction to anti-TNF treatment.
Ophthalmologic evaluation highlighted keratic precipitate, Tyndall effect, hypopyon, and visual loss (right eye 20/50, left eye 20/32). Given the persistence of ocular inflammation and the recurrence of arthritis, we decided to introduce ADA ( $24 \mathrm{mg} / \mathrm{m}^{2}$ every 2 weeks) associated to MTX $\left(15 \mathrm{mg} / \mathrm{m}^{2}\right.$ weekly). This protocol ensured a stable clinical remission over 16 months. Thereafter, she flared again and recrudescence of ocular inflammation along with arthritis reactivation were detected. Treatment with ABA (10 mg/kg every 4 weeks) and MTX was started, leading to poor clinical control and a new uveitis flare in the left eye with the development of cataract and cystoid macular edema. Because of the recurrence of uveitis and the persistence of arthritis, after an 8-week washout period, ABA was switched to canakinumab.

Both children received intravenous methylprednisone $(30 \mathrm{mg} / \mathrm{kg}$ for 3 days) followed by maintenance therapy with oral prednisone $(0.25-1 \mathrm{mg} / \mathrm{kg}$ daily) and canakinumab ( $2 \mathrm{mg} / \mathrm{kg}$ monthly). Patient 2 received concomitant therapy with MTX, which was discontinued after 6 months from the introduction of canakinumab. Ocular remission was achieved with vision improvement, and oral steroid therapy was tapered after 2 months and discontinued after 4 months in Patient 1 and 10 months in Patient 2. During the 12-month period of followup, no new uveitis flares occurred. Visual acuity normalized in both patients (right eye 20/25, left eye 20/20). Intraocular pressure persisted within normal limits. Optical coherence tomography excluded the recurrence of cystoid macular edema (Figure 1B). The therapy has been well tolerated without major side effects, infusion reactions, or drug-related adverse events.

According to the other cases reported in the literature, our experience suggests a potential involvement of canakinumab in maintaining remission in children affected by severe sight-threatening uveitis refractory to previous biological treatments. To our knowledge, ours is the first report of the use of canakinumab for pediatric uveitis.

ALICE BRAMBILLA, MD, Rheumatology Unit, Azienda Ospedaliero Universitaria (AOU) Anna Meyer Children's Hospital; ROBERTO CAPUTO, MD, Ophthalmology Unit, AOU Anna Meyer Children's Hospital; ROLANDO CIMAZ, MD, Rheumatology Unit, AOU Anna Meyer Children's Hospital; GABRIELE SIMONINI, MD, Rheumatology Unit, AOU Anna Meyer Children's Hospital, Florence, Italy. Address correspondence to Dr. A. Brambilla, AOU Anna Meyer Children's Hospital, viale Pieraccini 24, Florence, Italy.

E-mail: alice.brambilla02@ateneopv.it

\section{REFERENCES}

1. Simonini G, Cantarini L, Bresci C, Lorusso M, Galeazzi M, Cimaz
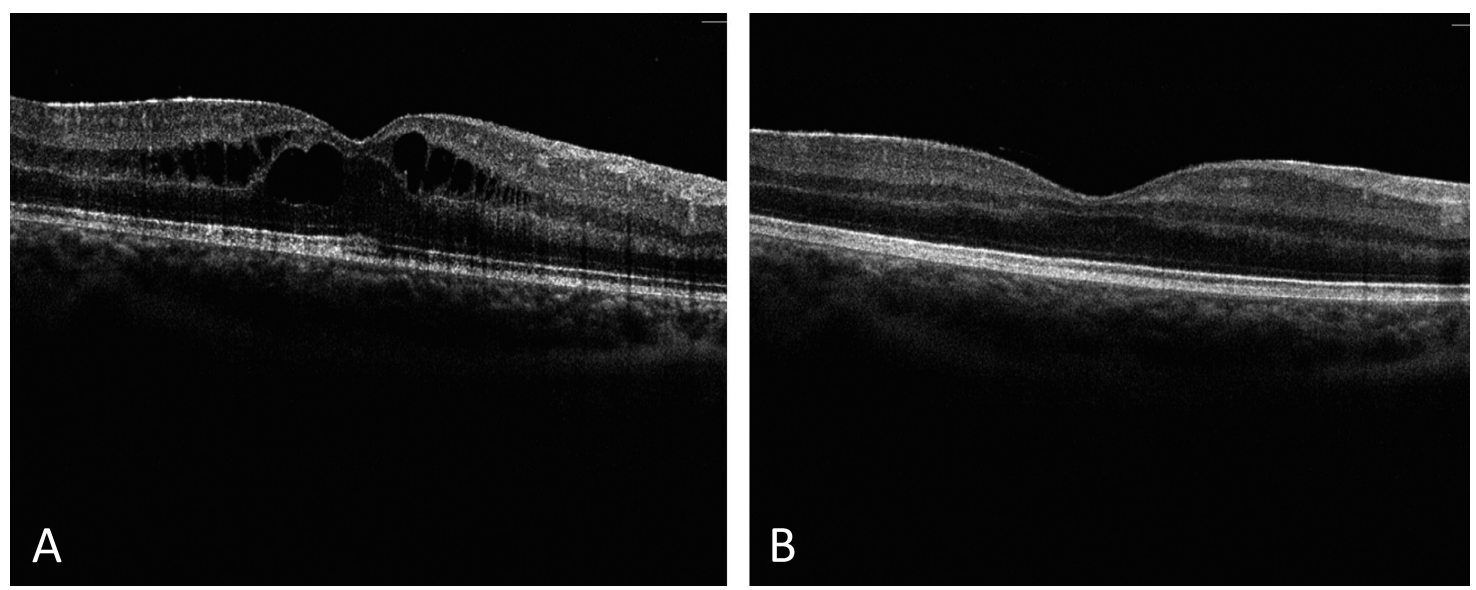

Figure 1. Optical coherence tomography images at right eye show retinal morphology evolution (A) before and (B) after canakinumab. A. Severe cystoid macula edema. B. Complete resolution in exudation along with mild derangement of the outer plexiform and nuclear layers. 
R. Current therapeutic approaches to autoimmune chronic uveitis in children. Autoimmun Rev 2010;10:674-83.

2. Simonini G, Cimaz R, Jones GT, Macfarlane GJ. Non-anti-TNF biologic modifier drugs in non-infectious refractory chronic uveitis: The current evidence from a systematic review. Semin Arthritis Rheum 2015;45:238-50.

3. Lachmann HJ, Kone-Paut I, Kuemmerle-Deschner JB, Leslie KS, Hachulla E, Quartier P, et al; Canakinumab in CAPS Study Group. Use of canakinumab in the cryopyrin-associated periodic syndrome. N Engl J Med 2009;360:2416-25.

4. Ruperto N, Brunner HI, Quartier P, Constantin T, Wulffraat N, Horneff G, et al; PRINTO; PRCSG. Two randomized trials of canakinumab in systemic juvenile idiopathic arthritis. N Engl J Med 2012;367:2396-406.

5. Pagnini I, Bondi T, Simonini G, Giani T, Marino A, Cimaz R Successful treatment with canakinumab of a paediatric patient with resistant Behcet's disease [letter]. Rheumatology 2015;54:1327-8.

6. Vitale A, Rigante D, Caso F, Brizi MG, Galeazzi M, Costa L, et al. Inhibition of interleukin-1 by canakinumab as a successful mono-drug strategy for the treatment of refractory Behcet's disease: a case series. Dermatology 2014;228:211-4.
7. Brik R, Butbul-Aviel Y, Lubin S, Ben Dayan E, Rachmilewitz-Minei T, Tseng L, et al. Canakinumab for the treatment of children with colchicine-resistant familial Mediterranean fever: a 6-month open-label, single-arm pilot study. Arthritis Rheumatol 2014;66:3241-3.

8. Simonini G, Xu Z, Caputo R, De Libero C, Pagnini I, Pascual V, et al. Clinical and transcriptional response to the long-acting interleukin-1 blocker canakinumab in Blau syndrome-related uveitis. Arthritis Rheum 2013;65:513-8.

9. Ugurlu S, Ucar D, Seyahi E, Hatemi G, Yurdakul S. Canakinumab in a patient with juvenile Behçet's syndrome with refractory eye disease. Ann Rheum Dis 2012;71:1589-91.

10. Hirano M, Seguchi J, Yamamura M, Narita A, Okanobu H, Nishikomori R, et al. Successful resolution of stromal keratitis and uveitis using canakinumab in a patient with chronic infantile neurologic, cutaneous, and articular syndrome: a case study. J Ophthalmic Inflamm Infect 2015;5:34.

J Rheumatol 2016;43:7; doi:10.3899/jrheum.160064 